\title{
A PESQUISA-INTERVENÇÃO PSICANALÍTICA COM ADOLESCENTES: O QUEELASNOS DIZEM SOBRE GRAVIDEZ E MATERNIDADE A PARTIR DA CONVERSAÇÃO ${ }^{1}$
}

THE PSYCHOANALYTIC INTERVENTION RESEARCH WITH ADOLESCENTS: WHAT THEY TELL US ABOUT PREGNANCY AND MOTHERHOOD FROM THE CONVERSATION

LA INVESTIGACIÓN-INTERVENCIÓN PSICOANALÍTICA CON ADOLESCENTES: QUÉ NOS DICEN SOBRE EMBARAZO Y MATERNIDAD A PARTIR DE LA CONVERSACIÓN

\author{
Cristina Moreira Marcos ${ }^{*}$ \\ Renata Lucindo Mendonça
}

\begin{abstract}
RESUMO
Buscamos interrogar, pela discussão de alguns casos, o sentido, na atualidade, da gravidez na adolescência. Se as adolescentes, hoje, podem viver uma certa liberdade sexual sem engravidar, por que ainda a gravidez, nesse período da vida, continua acontecendo e é considerada um problema pela sociedade e pelas políticas públicas em todo o mundo? E, principalmente, por que as adolescentes engravidam? Essa questão é abordada pela perspectiva da psicanálise. A prática da conversação, metodologia adotada por nós, mantém o objetivo psicanalítico de escutar o inconsciente e unir o tratamento à pesquisa e, desse modo, permite-nos examinar o sentido e a função da gravidez com base na singularidade e na palavra de cada um, e interrogar nossa hipótese: se a gravidez na adolescência poderia ser, em alguns casos, uma resposta ao ser mulher e um endereçamento ao Outro.
\end{abstract}

Palavras-chave: Psicanálise. Adolescência. Gravidez. Maternidade.

\begin{abstract}
We sought to question, from the discussion of some cases, the meaning of pregnancy in adolescence today. If adolescents today can live a certain sexual freedom without becoming pregnant, why is pregnancy in this period of life still happening and is considered a problem by society and public policies around the world? And, mainly, why do the adolescents get pregnant? This problem is approached from the perspective of psychoanalysis. The practice of the Conversation, methodology adopted by us, maintains the
\end{abstract}

\footnotetext{
Texto recebido em 3 de julho de 2017 e aprovado para publicação em 10 de novembro de 2017.

1 Este artigo é resultado da dissertação de mestrado “A gravidez na adolescência: uma resposta ao Outro?”, defendida no Programa de Pós-Graduação em Psicologia da PUC Minas, e integra a pesquisa "O que quer a mãe hoje: um estudo da maternidade no século XXI a partir da psicanálise", financiada pela Fapemig.

Doutora em Psicanálise pela Universidade de Paris 7, docente do Programa de Pós-Graduação em Psicologia da PUC Minas, psicanalista.

** Mestra em Processos de Subjetivação pelo Programa de Pós-Graduação em Psicologia da PUC Minas, psicanalista.
} 
psychoanalytical objective of listening to the unconscious and uniting the treatment to the research. It allowed us to examine the meaning and function of pregnancy from the singularity of each one and to question our hypothesis: If pregnancy in adolescence could in some cases be a response to be a woman and an address to the Other.

Keywords: Psychoanalysis. Adolescence. Pregnancy. Maternity.

\section{RESUMEN}

Buscamos interrogar, a partir de la discusión de algunos casos, el sentido en la actualidad del embarazo en la adolescencia. Si las adolescentes, hoy, pueden vivir una cierta libertad sexual sin quedar embarazadas, ipor qué aún el embarazo, en ese período de la vida, continúa sucediendo y es considerado un problema por la sociedad y por las políticas públicas en todo el mundo? Y, sobre todo, ¿por qué las adolescentes se embarazan? Este problema se aborda desde la perspectiva del psicoanálisis. La práctica de la conversación, metodología adoptada por nosotros, mantiene el objetivo psicoanalítico de escuchar lo inconsciente y unir el tratamiento a la investigación. Nos permitió examinar el sentido y la función del embarazo a partir de la singularidad y la palabra de cada uno e interrogar nuestra hipótesis: Si el embarazo en la adolescencia podría ser, en algunos casos, una respuesta al ser mujer y un direccionamiento al Otro.

Palabras clave: Psicoanálisis. Adolescencia. Embarazo. Maternidad.

\section{INTRODUÇÃO}

$\mathrm{H}$ á milênios, encontram-se registros de ideias anticonceptivas. As primeiras foram pensadas por Aristóteles (Nogueira, 2009). Podemos afirmar que ter relações sexuais somente pelo prazer, pelo encontro sexual, é uma questão antiga, anterior ao mundo em que vivemos. Entretanto a pílula anticoncepcional foi uma invenção do mundo moderno e é um marco na história da civilização no que se refere ao controle de natalidade. Ela foi lançada em 18 de agosto de 1960 (Hartl, 2017), há poucas décadas. Foi um avanço científico e foi responsável por uma mudança fundamental no comportamento das mulheres. Essa invenção possibilitou a escolha de engravidar ou não e em qual momento um filho seria pertinente na vida de uma mulher.

Por quê, na atualidade, com o avanço dos métodos anticonceptivos, existe ainda a gravidez precoce e indesejada? Por quê, na atualidade, as adolescentes, que podem viver experiências sexuais sem a consequência da gravidez, continuam engravidando? A gravidez precoce e, ou, indesejada é considerada, pelas políticas 
públicas, um problema, principalmente quando nos referimos à parcela da população que engravida na adolescência. As cartilhas, os cursos e o acesso a anticoncepcionais são projetos educativos adotados por vários governos como tentativa de eliminar ou diminuir a incidência da gravidez nas circunstâncias mencionadas acima.

Escolhemos como base teórica a psicanálise, por ser a teoria que nos permite abordar a questão com base na singularidade do sujeito e de suas determinações inconscientes. O sujeito da psicanálise não é senhor de suas ações, o saber da consciência cumpre um papel mínimo em seu sintoma; ao contrário, ele é determinado por um não saber, considerado fundamental na relação do sujeito com o mundo. Assim, não podemos tratar um fenômeno, seja este social ou histórico, sem considerar o caso a caso. É nessa perspectiva que a gravidez na adolescência será abordada neste artigo. Interessa-nos interrogar o sentido da gravidez e da maternidade para cada adolescente.

Por isso escolhemos como método de intervenção e pesquisa a conversação. Esta é um dispositivo criado por Jacques-Alain Miller na década de 1990, que tinha como objetivo abrir campo para a palavra entre os psicanalistas. Segundo ele, a conversação é:

Uma situação de associação livre, se ela é exitosa. A associação livre pode ser coletivizada na medida em que não somos donos dos significantes. Um significante chama outro significante, não sendo tão importante quem o produz em um momento dado. Se confiamos na cadeia de significantes, vários participam do mesmo. Pelo menos é a ficção da conversação: produzir - não uma enunciação coletiva - senão uma associação livre coletiva, da qual esperamos um certo efeito de saber. Quando as coisas me tocam, os significantes de outros me dão ideias, me ajudam e, finalmente, resulta - às vezes - algo novo, um ângulo novo, perspectivas inéditas (Miller, apud Alvarez, 2005, p. 15-16, tradução do autor).

Nesse dispositivo, o que nos interessa é a palavra, a autorização para que ela circule entre nós e, assim, possamos recolher algo do inconsciente do sujeito. Com esse modo de funcionar, a psicanálise circula também pela cidade e escuta os sujeitos nos locais em que ele vive, trabalha ou se reúne. Esse dispositivo tem como finalidade a oferta da palavra (Lacadée, 2007a). A conversação mantém o objetivo psicanalítico de escutar o inconsciente e unir o tratamento à pesquisa. Esse dispositivo visa a produzir um tratamento do gozo a partir do momento em que reconhece e respeita a singularidade e a palavra de cada um, dando um lugar peculiar para o simbólico: 
O dispositivo pode fazer operar "uma prática inédita da palavra", que, segundo ele, tenta subverter o laço social daqueles que, de alguma maneira, foram confinados ao silêncio excludente marcados por identificações. O que as conversações propõem é "destravar as identificaçōes”, isto é, no trabalho desenvolvido, a palavra pode mostrar aos sujeitos que ali se encontram aquilo pelo qual estão tomados e, quem sabe, apostar que podem livrar-se do gozo em que estão aprisionados (Miranda, Vasconcelos \& Santiago, 2006, p. 3).

Podemos dizer que a conversação tenta causar uma desindentificação ou identificação aos seguintes e possíveis significantes: gravidez, maternidade, adolescência. Com isso, pode recriar uma nova identificação ou um modo particular de lidar com esses significantes, pois não se trata de buscar ideias compartilhadas nas quais caiba uma única solução comum a todos. O que está em jogo em uma conversação é o encontro com o cada um.

A conversação faz uma diferença e um corte no modo com que as instituições nas quais recolhemos o material funcionam, pois todos os cursos dados e o modo como elas tratam a gravidez, nesse período da vida, estão condizentes com as políticas públicas e com o modo como as políticas veem o adolescente: como aquele que deve ser conduzido e ensinado, de uma forma pedagógica. Assim, a conversação subverte isso. Nela, o que nos interessa é o não sabido, não há um saber pronto a ser entregue ou ensinado. Nesse dispositivo, apostamos no mal-entendido, no fora do sentido, no furo do dizer como uma "ausência fundamental".

O Centro Interdisciplinar de Estudos sobre a Criança e a Adolescência (CIEN), o qual usa a conversação como dispositivo, foi criado na França, em julho de 1996. Desde sua criação, ele causa uma inversão do saber e da forma, pois o seu modo de operar não é falando das crianças e adolescentes, mas falando com elas. As crianças e os adolescentes são detentores do saber. Diferente do modo como as políticas públicas e outros discursos tratam a criança e o adolescente, como aqueles a serem guiados, a conversação autoriza que o saber venha desses sujeitos, que estes possam criar soluçóes para suas questões e nos ensinarem, nos mostrarem sobre as questôes que lhes tocam. Assim, "não é solicitado um saber já sabido, predeterminado, pois a fala é própria de cada sujeito" (Miranda et al., 2006, p. 6).

O material recolhido das gestantes e mães escutadas refere-se a adolescentes entre 13 a 17 anos, com caraterísticas sociais e econômicas semelhantes. As conversações foram realizadas em uma Organização não governamental (ONG) que atende e acolhe gestantes e mães adolescentes. Nela, as adolescentes recebem diversos cuidados assistenciais (educação e assistência médica), abrigo e condições materiais para cuidar de seu bebê. Em contrapartida, a adolescente deve se 
comprometer a cumprir as regras institucionais e a dedicar-se integralmente a seu filho, à vida escolar e doméstica. Foram realizadas 7 conversaçōes, com um número de participantes que variou entre 5 a 7 a cada encontro. Foram feitos registros escritos pela pesquisadora após cada conversação, assim como supervisões clínicas e orientações no âmbito da pesquisa de mestrado. Com base nesse material clínico, foi possível investigar a gravidez na adolescência, a partir do um a um, traçar e verificar nossa hipótese: seria a gravidez na adolescência uma reposta endereçada ao Outro?

\section{O ENCONTRO COM AS ADOLESCENTES: O QUE ELAS PODEM NOS ENSINAR?}

Os fragmentos recolhidos permitiram abordar a gravidez na adolescência a partir do um a um, diferentemente de uma compreensão generalizada, priorizando o caso a caso e a singularidade de cada sujeito. É na construção de cada caso que se pode averiguar o estatuto e a função da gravidez e, com isso, verificar nossa hipótese: se a gravidez na adolescência pode ser, em alguns casos, um endereçamento ao Outro ou um modo de passagem da vida infantil para a vida adulta. Seria uma resposta ao ser de mulher?

\section{3. "ENGRAVIDEI E PAREI COM TUDO!”}

Lívia é uma garota de 17 anos que já passou por vários abrigos e instituições. Tem uma relação longa com a Justiça e com os atos infracionais. Ela nos conta que morava em uma cidade próxima da capital e, um dia, quando ela tinha 11 anos de idade, a mãe a levou ao Conselho Tutelar e disse ao juiz que não a queria. Lívia nos relatou: "Ela fala que não queria ser minha mãe".

Perguntamos a essa adolescente o que estava acontecendo antes desse fato. Ela nos contou que ela saía à noite, chegava de manhã em casa e que não a obedecia. Podemos dizer que o corpo de Lívia já se encontrava nas ruas e que havia um gozo sem nome já aos 11 anos? O que podemos saber, pela fala dela, é que a relação com a mãe não organizava essa garota, que a mãe não podia lidar com aquilo. Podemos afirmar, nesse caso, que essa adolescente não tinha lugar no desejo da mãe, não ocupava o lugar de filha.

Após o encontro com o juiz, ela ficou um tempo em uma casa provisória, de amigos, e, ao voltar para casa, constatou que a mãe fora embora: "Ela me deixou com um fogão e um colchão, fui para a rua e não quis saber de mais nada. Eu enlouqueci!". 
Sobre a trajetória nas ruas, relatou: "Eu tomava do outro para ter o que é meu”. O que ela queria tomar do Outro? Já que o que ela tomava ela o via como um direito, o que ela tomava já era dela ("para ter o que é meu")? Para além dos objetos de consumo e das privaçóes de uma adolescente que vivia nas ruas, poderíamos pensar que existia uma dívida do Outro para com ela. Seria uma dívida simbólica? Ela queria uma coisa do Outro. Ela recebia da mãe, do Outro primordial, um lugar vazio. O Outro não me deu, eu vou tomar. Eu arranco do Outro. Parece que o que Lívia viveu, sua construção com a imago fundamental materna, surgiu direcionado ao outro da rua.

Para a psicanálise, a questão da agressividade se dá de forma subjetiva, relacionada à construção do Eu no narcisismo e relacionada às imagos infantis, assim

Basta o pretexto mais fortuito para provocar a intensão agressiva que reatualiza a imago, instalada permanentemente no plano de sobre determinação simbólica a que chamamos o inconsciente do sujeito, com sua correlação intencional (Lacan, 1948/1998, p. 110)².

Podemos afirmar que toda violência e agressividade dirigida ao Outro se relaciona "em cada caso, a uma organização original das formas do eu e do objeto" (Lacan, 1998, p. 113).

No caso de Lívia, ela nos ensinou que toda a construção infantil, a sua relação com as imagos infantis surgiu na relação com o mundo de forma agressiva. No texto A agressividade em psicanálise, Lacan reafirma que, na construção do Eu, é impossível não passar pela agressividade, que essa é uma construção primordial feita sobre a mãe que tem a "função do recinto imaginário primordial formado pela imago do corpo materno" (Lacan, 1998, p. 117). Para ele, temos com a mãe uma cartografia e com as imagos do pai e dos irmãos, e a história da criança um atlas a partir do qual conhecemos os modos que o sujeito construiu seu Eu e os modos de sua agressividade.

Sobre o modo de agir nas ruas, além de "tomar do outro para ter o que era dela", ela nos avisou que, "em turma ou sozinha, não levava desaforo pra casa", além de dizer que o melhor era "matar com faca", fato que ela relatou com detalhes, pois podemos afirmar que a agressividade, para a psicanálise, é subjetiva, é uma experiência que somente faz sentido para o próprio sujeito.

Poderíamos nos perguntar sobre o gozo presente naquele momento da vida de Lívia, pois "o que chamamos de gozo é a satisfação imaginária" (Miller, 2012b, p. 88). Essa adolescente repetia sem palavras e de modo especular uma ação A primeira data indica o ano de publicação original da obra e a segunda data indica a edição consultada pelo autor; que só será pontuada na primeira citação da obra no texto. Nas seguintes será registrada apenas a data de publicação original. 
contra o Outro. Desse modo ela dava uma inconsistência ao Outro. Um "furo de faca", matar com faca e "sentir a faca entrando em todas as camadas". Se a pessoa morreu não sabemos, mas seria tentar matar o Outro a cada vez. "O gozo "enquanto distinto da satisfação simbólica, nós o encontramos no eixo a-a"” (Miller, 2012b, p. 88). Esse gozo apresentado por Lívia não era dialético, era "permanente, estagnante e inerte", e sua emergência era quando a elaboração "simbólica falhava ou fracassava", somente dessa forma que imaginariamente esse gozo se repetia, sem sentido e com uma satisfação particular.

A rua era um lugar pelo qual ela circulava, ela existia, pois, além de relatar a violência presente e o seu modo de agir, relatava os laços feitos principalmente com os técnicos que ela encontrou nos vários abrigos ou instituiçôes que passou. $\mathrm{Na}$ rua, nesse período, reconheceu e soube das leis, soube dos seus direitos perante a lei e se localizou nos lugares da cidade. Seria a rua, mesmo com tanta violência, um lugar no qual ela tinha uma inscrição? Consideramos que, para além de todo horror relatado, essa garota fazia laços, localizava-se com os técnicos, nomeava pessoas, nomeava-se ao circular nas ruas e isso se apresentava, era visto e demonstrado na instituição.

Amorosamente teve seus primeiros encontros com as meninas: "Eu era sapata, só ficava com menina. Hoje o que me importa é se tratam bem a mim e ao meu filho". Podemos lembrar com Freda (2015) que "Já não se trata tanto de heterossexualidade ou de homossexualidade, sim de 'onde me sinto mal'” (p. 16, tradução do autor).

Em relação à gravidez, ela nos disse que engravidou de um rapaz tão violento quanto ela e que engravidar teve um efeito, pois ela nos relatou que: "Quando eu engravidei, eu parei com tudo". Questionada, disse: "Eu parei com as drogas, com a bebida, eu parei com tudo, só pensava nele, no meu bebê". É interessante percebermos que, nas ruas, ela podia circular, encontrar pessoas e se nomear, mas isso não fazia com que a violência em relação ao Outro e a si mesma cessasse. $\mathrm{O}$ ponto de basta foi a gravidez e, mesmo parando com o uso abusivo de drogas, ela continuava nas ruas. Ela somente saiu das ruas quando o bebê nasceu no hospital. Quando ela ganhou o bebê, após o parto, ainda no hospital, ela foi encaminhada para a ONG a partir da evidência dos atos infracionais mostrados pelos boletins de ocorrência e foi para a instituição que acolhia a mãe adolescente e seu bebê.

Foi nos contando, nas conversações, o que queria para o filho e como queria criá-lo. Afirmou que apenas ela e a avó podiam chamar a atenção da criança: "Mais ninguém vai chamar a atenção dele!". E perguntamos: "Você e sua mãe. E o pai dele?". E ela retrucou rapidamente: "Não! A mãe do pai dele (a sogra dela), que é como uma mãe pra mim. E o que ela compra pra filha dela ela compra pra mim”. 
No caso de Lívia, os acting, em sua trajetória de rua, como um apelo ao Outro não foram suficientes para tratar o gozo que se apresentava no corpo. Apesar dos laços feitos com os técnicos e nos abrigos, não ocorreu uma construção de um lugar menos violento. Foi a partir da gravidez que isso foi possível. Nas ruas, ela passou por várias instituições, estabeleceu laço com vários técnicos e se localizava nas ruas da cidade, mas foi a partir da maternidade que ela pôde suportar as leis da instituição.

Poderíamos afirmar que, com a presença do filho, ela encontrou um Outro que podia acolhê-la de um novo modo. Foi a partir do filho que um novo laço se fez, um laço particular que deu a ela um lugar singular, diferentemente do lugar de infratora, fora da lei, que era reconhecido tanto nas ruas quanto na relação com a mãe até os 11 anos de idade.

Além da instituição, que somente se constituiu para ela como um lugar a partir da maternidade, houve o lugar íntimo que foi a relação dela com a sogra, que se constituiu, também, a partir da maternidade. Tornou-se para ela impossível abandonar aquele bebê com o qual ela se identificava. Foi a maternidade que lhe conferiu o lugar não de mãe, mas de filha junto à sogra. Assim, em vez de uma identificação marcada pela agressividade, passava a ter uma identificação pela maternidade, a partir do encontro dela com sua sogra, ela cuidou do bebê, quando ela engravidou, "parou com tudo", somente pensava no bebê, mas, foi apenas através do encontro com a sogra que ela pôde se haver com a maternidade de um modo que fosse uma solução fora da violência.

Com isso, talvez, ela pudesse tratar o seu lugar de filha, no íntimo e particular da relação com a sogra, um tratamento diferente daquele que a rua pôde lhe dar. A maternidade pareceu tirar Lívia das atuações e da violência, podendo ser uma saída mais próxima da vida que do enlouquecimento e da agressão.

\section{4. "SOMOS TODOS IGUAIS!"}

Júlia tinha 15 anos e estava grávida do segundo filho. Em uma conversação, relatou que as pessoas a nomearam "irresponsável" por ela ter engravidado pela segunda vez. O que as pessoas não sabiam e o que ela nos contou foi que a primeira gravidez foi com o padrasto: "Foi um estupro". Ao relatar esse acontecimento, disse que não fez aborto porque o bebê não tinha culpa e que sua mãe não a responsabilizou, dizendo-lhe que a culpa não era dela. Além disso, afirmou que seu primeiro filho era inocente e que o amava muito.

Nessa segunda gravidez, ela se sentia feliz. Relatou que, antes de engravidar, "andava pelas ruas da cidade por toda a noite". Perguntamos por que ela 
andava pela rua e o que ela fazia durante a noite nessas andanças. Júlia nos relatou que "andava por andar", mostrou seu percurso de andarilha, por onde caminhava, e afirmou: "Eu conversava com todos". Questionada sobre quem eram "todos", ela nomeou alguns: "Os policiais". Relatou isso sem implicações, sem questionamento, como algo que fazia parte da vida. Andava pelas ruas à noite, nos lugares mais perigosos da cidade.

Júlia disse que agora era feliz. Ela estava casada com o pai de seu próximo filho, que tinha 16 anos, e os dois viviam em uma casa com seu primeiro filho e sua sogra, "que a tratava como uma filha". Reafirmou o quanto estava feliz morando naquela casa e que os três, ela, o namorado e o filho, eram muito "brincalhôes" e nada comportados.

As adolescentes disseram, na conversação, "que era bom os dois (ela e o namorado) cuidarem do seu primeiro filho", mas ela retrucou: "Nada! A gente é quase como criança, quando tem chocolate então [...] Ganhamos chocolates e ficamos nós três, eu, meu namorado e meu filho brigando pelo chocolate. Ali somos todos iguais".

Podemos supor que Júlia, mesmo após a segunda gravidez, não se localizava com um saber sobre um novo lugar, não tendo atravessado o momento de passagem da adolescência para o mundo adulto. A gravidez não se constituiu, para essa jovem, como um rito de passagem, como uma resposta ao ser de mulher. Júlia passava por aquele acontecimento no corpo sem uma pergunta sobre si mesma, sobre o seu lugar. Consideramos importante observar o que ela apontou no início da conversação, que nos pareceu ser uma questão para ela, que era a nomeação que ela recebeu do Outro, "irresponsável", e quando ela disse, em relação à primeira gravidez: "Minha mãe disse que não foi minha culpa". Verificamos que Júlia questionava mais o lugar de filha que o lugar como mãe ou mulher. Ela existia, então, mais como um dos irmãos, entre "os iguais", sendo a sogra quem exercia a função de mãe para os três.

Mesmo tendo passado por duas gestações, isso não tinha efeito sobre o sujeito de um atravessamento, um rito de passagem que pudesse nomeá-la de outro modo. A gravidez não apresentava significantes novos para Júlia. $\mathrm{O}$ primeiro filho, do padrasto, surgiu como um irmão mais novo de Júlia, do qual ela precisava cuidar: "Somos todos iguais", "Somos brincalhões", "Brigamos por chocolate". O encontro com a nova família deu a Júlia uma mãe, por meio da sogra, e ela passou a existir como mais uma filha.

A primeira gravidez surgiu com um acontecimento que ela nomeou como "estupro". Não foi possível localizar se essa nomeação era dela, se era uma nomeação própria ou se era do Outro. Não conseguimos escutar o que significou 
esse "estupro", somente que ela teve, a partir do nascimento do filho, um irmão. Sobre a mãe, Júlia disse mais de uma vez: "Ela não me considerou culpada". $\mathrm{Na}$ conversação, não tivemos a chance de escutar melhor como se deu a relação dela com a mãe biológica e com o padrasto, pai de seu primeiro filho. Todavia, ficou claro que um dos primeiros efeitos desse acontecimento foi uma errância pelas ruas da cidade. Houve uma predominância do agir, um corpo que saía andando e conversando, principalmente com os policiais. Um acting out? Não seria um modo de ficar às voltas com a lei e se proteger?

O que barrou esse corpo e pôde dar um lugar para essa adolescente foi a segunda gravidez, que aconteceu de um outro modo. Ela engravidou de um rapaz próximo de sua idade, um adolescente como ela, e encontrou uma nova família. Uma sogra que a acolhia "como se fosse sua filha", assim como acolhia seu primeiro filho, seu irmão. Ao encontrar uma sogra que pôde fazer a função de mãe, ela se tornou filha novamente.

\section{5. "DEPOIS QUE ENGRAVIDEI, TUDO MUDOU”}

Cris, uma jovem de 14 anos, estava em sua primeira gravidez. No único encontro com a psicóloga, relatou que era a filha mais velha de dez irmãos, que sempre ajudou a mãe nos cuidados com estes e com a casa, mas que a mãe nunca estava satisfeita com ela: "Nós duas brigávamos muito". Depois de um tempo, por causa das brigas, ela decidiu morar com o pai. Como não deu certo, ela foi morar com o namorado, com quem estava no período deste encontro.

Ela relata que, após a gravidez, "tudo mudou": "Minha mãe agora conversa comigo, me diz como fazer para cuidar de uma casa e de um marido. Meu pai me ajuda me dando dinheiro quando eu preciso - tudo mudou”. No final da sessão, ela ainda nos contou que ganharia um presente que sempre quis de sua mãe: uma boneca. Cris estava às voltas com o seu lugar no desejo do Outro e tentava, de várias formas, "satisfazer" a mãe. Ela precisava de um lugar no Outro familiar e encontrou um lugar como filha a partir da gravidez. Antes da gravidez, ela era mais uma entre os dez irmãos, a mais velha que se ocupava dos afazeres da casa, mas que não era legitimada como filha pela mãe.

A pergunta sobre o seu lugar no desejo da mãe estava mais clara e precisa do que uma pergunta sobre o seu ser de mulher para um homem. Ela nos disse: "Minha mãe está me ensinando a cuidar de uma casa e de um marido". Como ela já cuidava de uma casa e já morava com o namorado antes de engravidar, o que estava em jogo era o olhar da mãe sobre ela e não a relação dela com um homem ou o que poderia significar ser uma mulher. Ao mesmo tempo, encontrar o seu ser de mulher também passava por uma transmissão, pelo olhar do Outro e pelo lugar que uma Outra podia ter para uma adolescente. 
Perguntamos se o que importava para Cris era que aquilo fosse transmitido por sua mãe, uma transmissão do que poderia ser uma mulher. Pudemos também localizar aqui a imiscuição do adulto na criança, já que a menina bancava a mulher desde cedo, embora isso não significasse que houvesse uma resposta sobre o seu ser de mulher.

Antes de uma passagem ao ato, há um agir, que chama o Outro para um olhar, que convoca o Outro para que este dê um lugar para o adolescente. Os acting de Cris eram as brigas com a mãe, morar com o pai e morar com o namorado aos 13 anos de idade. Acreditamos que esses atos eram maneiras de convocar o olhar do Outro. O que era interessante no caso de Cris era que não eram os acting out que permitiam ao sujeito fazer uma travessia para o mundo adulto. Ela estava às voltas com o seu lugar no Outro familiar. Se não havia um lugar no Outro familiar, se ela não ocupava, imaginariamente, o lugar de objeto fálico para a mãe, um lugar de exceção, que era possível, mesmo sendo uma filha entre dez irmãos, como ela iria se separar para encontrar o seu nome e seu lugar no mundo adulto, fora do familiar?

Nas operações de alienação e separação, a separação é uma resposta à alienação. "A primeira, a alienação, é própria e mesmo puramente de ordem simbólica, [...] o resultado desta operação implica, necessariamente, uma resposta de gozo - a separação" (Miller, 2012b, p. 93). Sabemos que esse trabalho já foi realizado na tenra infância, quando nos referimos a sujeitos que foram atravessados pelo discurso, que estão às voltas com o falo e que atravessaram o complexo de Édipo, não havendo a foraclusão do Nome do Pai. Entretanto, na puberdade, ocorre uma falha do que foi construído na tenra infância, e o sujeito precisa inventar um nome a partir da construção infantil, mas tendo de se dirigir ao mundo fora do contexto familiar e tendo de lidar com a pulsão sexual e terna.

No caso de Cris, pareceu-nos que os acting out e a gravidez funcionaram como uma tentativa para encontrar o seu lugar de alienação ao Outro, mesmo que a operação de alienação e separação já tivesse acontecido na tenra infância. Ela saiu de casa, morou com o pai, morou com o namorado, mas isso não se configurava como uma tentativa de encontrar no mundo uma identificação, sendo mais um apelo ao Outro do que uma travessia. "É possível falar de 'acting out' quando há uma cena que é a fala, e o sujeito se põe a agir diante do Outro nessa cena. É preciso o Outro, é preciso o espectador" (Miller, 2014, p. 7). Todas as cenas de briga com a mãe e de ir de casa em casa foram relatadas pela jovem sem que ela explicitasse o que a interessava fora do núcleo familiar. Que mundo era aquele que ela gostaria de encontrar? Cris descreveu os acontecimentos mais como um horror e um abandono do que com um brilho ou interesse pelo mundo exterior. Freud (1905/1996) nos ensina que, na puberdade, algo se desloca e o mundo 
fora passa a ter um brilho. Parece-nos que o mundo fora ainda não tinha brilho para essa adolescente. Ele afirma que, na infância, o que a criança quer é se identificar com os pais, e que mesmo que a fantasia, que o romance familiar seja uma separação do par parental, a identificação com os pais ainda é necessária. Somente na puberdade, quando a fantasia vacila, não responde, não nomeia o gozo, há uma queda na identificação, e, como nos esclarece Freud (1914/1996), o par parental perde o brilho. Aquela adolescente não procurava uma identificação fora, uma resposta sobre si mesma como um rito de passagem para o mundo adulto, isso não advinha. $\mathrm{O}$ que ela nos dizia era que ela encontrara um lugar no desejo do Outro materno. Com a gravidez, Cris ganhou um lugar de filha, tornou-se exceção, a filha/mãe entre os dez filhos. Talvez a travessia somente ocorresse a partir da transmissão do que era ser uma mulher feita por uma outra que, naquele caso, diferente do "caso Dora", podia ser feita pela mãe. A gravidez de Cris era um apelo ao Outro que funcionava, que dava um lugar a ela como filha.

\section{CLARA: RECUSAR É SE RESPONSABILIZAR?}

"A maternidade é uma solução honrosa para a feminilidade? Honrosa, ela é. Mas, sob o ponto de vista analítico, será que é autêntica? É preciso aí diferenciar a mãe e a mulher" (Miller, 2015b, p. 13).

Clara é uma das adolescentes que esteve na conversação. Era uma garota calada, que, a cada palavra que dizia, a cada questionamento, ficava com os olhos marejados ou sorria e silenciava-se. Nas poucas vezes em que falou, contou-nos sobre o encontro sexual que teve aos 9 anos. Esse acontecimento foi questionado pelas adolescentes, que consideraram essa circunstância precoce. Aos 9 anos, uma pessoa é considerada criança pela civilização e, portanto, deve ser protegida. Além disso, uma criança não é considerada capaz de responder pelos seus atos; assim, um ato sexual nessa idade é considerado precoce e violento, reconhecido como um estupro ou um abuso sexual. Para conseguirmos escutar o que esse acontecimento significou para Clara, aguardamos, na conversação, sua resposta. Ela nos contou que não se tratara de um abuso ou de uma violência, mas de um encontro. Para a psicanálise, os encontros e desencontros ou os acontecimentos têm um efeito para cada sujeito, de forma particular. Orientados por essa via, pudemos escutar o relato de Clara sem dar a ele o mesmo significado dado pelas adolescentes presentes na conversação ou pela cultura e pela civilização atual.

Em outra conversação, as adolescentes começaram a se queixar da instituição e das leis estabelecidas. $\mathrm{O}$ modo como a $\mathrm{ONG}$ e seus funcionários trabalhavam foi questionado por elas, que o consideravam abusivo. Verificamos, na fala das 
adolescentes e nas normas impostas, que havia um ideal preestabelecido pela instituição. Havia uma normatização e adequação, principalmente em relação à maternidade e à sexualidade. Para serem boas mães e se manterem com seus filhos, deviam cumprir as normas e se adequarem a um ideal social, além de apagar suas questões sexuais. Essa posição não é exclusiva da ONG, é também uma posição das políticas públicas na atualidade. Clara não disse nada durante a conversação, ficando calada.

$\mathrm{Na}$ conversação, elas pediam uma intervenção. Pediam um encontro com a instituição e que eu funcionasse como intermediária na reunião. Disse a elas que eu também estava submetida às leis da instituição e às leis das políticas públicas, "todos nós estamos", mas que eu pensaria no que poderíamos fazer.

$\mathrm{Na}$ conversação seguinte, fui recebida pelas adolescentes com silêncio e uma estranheza. A conversação não aconteceu. Perguntei a elas sobre aquele silêncio. Ao terminar o encontro, fui chamada pela psicóloga da instituição, que relatou que, na semana anterior, Clara fora para a escola e não voltara, retornando no dia seguinte, "sem o uniforme, com uma roupa diferente, uma roupa curta, e não sabemos onde dormiu". Esse acontecimento foi uma circunstância difícil para a instituição. A psicóloga nos disse "que tudo que havia sido construído (para Clara), até aquele momento, foi desfeito".

Depois daquele dia, coincidentemente, na ocasião da próxima conversação, Clara teve uma reunião com familiares. Chegou no fim do encontro, muito angustiada, mas não disse sobre o ocorrido, respondendo somente o que perguntamos a ela. Questionamos se a reunião havia sido boa e se teria uma saída para o que não fora bom. Ela respondeu que não. Disse, chorando, que a reunião não fora boa e que não haveria uma boa saída.

Clara participou de mais uma conversação em que as adolescentes falavam o que queriam para si depois de saírem da instituição, o que fariam e o que desejavam para os seus filhos. Nessa conversação, falaram de um ideal materno e do que consideravam ser uma boa mãe para uma criança.

Após duas semanas, ao retornar à instituição para outra conversação, a psicóloga me chamou e relatou que Clara havia saído da ONG. Ela foi à coordenadora e disse que não iria mais ficar, anunciando sua decisão também à psicóloga que a atendia e ao Juiz de seu caso. Isso não foi feito sem palavras, foi dito aos três responsáveis pelo caso: instituição, psicóloga clínica e Juiz.

Depois de sua resolução, as adolescentes foram chamadas até a sala de reunião onde foi dito a todas que Clara sairia. Elas perguntam se ela iria para outro abrigo, e eles respondem que não, que ela sairia da instituição para a rua. A 
coordenadora anunciou que, naquele momento, elas abririam a porta para Clara. Em um ritual, as adolescentes foram até a porta de entrada da ONG, abriram a porta e se despediram. O bebê de Clara ficou na instituição. Até o momento da última conversação, as jovens se revezavam para cuidar dele.

$\mathrm{Na}$ conversação, perguntamos sobre esse acontecimento. Algumas disseram que ela precisou ser muito corajosa, que ela gostava muito do filho, mas elas sabiam que Clara não tinha ninguém para cuidar dela. Ela havia dito a uma das adolescentes "que sabia que não podia levá-lo, já que ela não tinha para onde ir, onde morar e que ninguém iria cuidar dela e do bebê".

Nesse fragmento, pareceu-nos que o que a políticas públicas pediam e ofereciam à Clara não respondia à sua questão como sujeito, ao seu lugar como mulher ou a uma saída da adolescência. Ela recusava o que era estabelecido pelo Outro.

Em um primeiro momento, Clara fugiu, não voltou para a instituição e abandonou o filho por um dia. Seria um acting? Podemos afirmar que o acting, para o adolescente, pode ser considerado, em alguns casos, um apelo ao Outro. Quando essa adolescente evadiu da instituição, o olhar se voltou para ela: "Tudo que havia sido construído até o momento se desfez". Com isso, o Juiz foi acionado e decidiu pelo seu retorno para a instituição. A avó, a psicóloga, todos os mecanismos foram acionados, mas isso não lhe respondeu, não a nomeou.

A partir desse fragmento, é necessário pensarmos o que significa a maternidade quando esse acontecimento não dá um lugar, não nomeia, e quando o sujeito não se apropria desse nome, ainda que seja, como no caso de Lívia, para encontrar um lugar como filha. É importante localizarmos que o efeito da gravidez e da maternidade para cada uma é singular.

Estar grávida não significa ser mãe, e Clara nos ensinou isso de forma evidente, pois ela foi acolhida e se deixou acolher em sua gravidez, embora a maternidade não tivesse o mesmo efeito para ela. Freud situa o bebê como um substituto do falo e teoriza que essa é uma solução para responder ao ser de uma mulher, é o encontro com o objeto.

Ao considerar o modo em que a castração se inscreve para o sujeito feminino, em termos do não-ter falo e, sobretudo, em função da equivalência simbólica entre o pênis e o filho, emerge a hipótese [...] de que a solução para a feminilidade é a maternidade (Santiago, 2015, p. 75). 
O filho seria uma resposta à castração, segundo a afirmação freudiana. No caso de Clara, um bebê não foi uma solução, não tendo se configurado como uma resposta para essa adolescente.

Santiago (2015) formula que a questão do desejo não pode ser colocada sobre a mãe e sim sobre a mulher, e que a maternidade passa pela "condição de ser mulher" (Santiago, 2015, p. 74). A mãe tem o bebê, a mulher deseja e pode fazer de um bebê uma causa, um objeto. Assim, o caso Clara interroga o que é uma mulher para além da mãe, e é necessário nos perguntarmos o que seria uma mulher para a psicanálise e fazer uma pequena distinção teórica dessa questão.

Quando a adolescente Clara retornou após a sua evasão, foi dito: "Ela volta sem uniforme, com uma roupa curta e não sabemos onde dormiu". Ela não voltou como a mãe ou a pudica, ela voltou como mulher. Em relação à Medeia, Laia afirma que "seu ato desmedido: só mesmo bárbara e bruxa cometeria tal desfaçatez" (Laia, 2015, p. 25). Esse argumento, "só bárbara e bruxa”, diz-nos muito de como uma mulher é vista. A mulher é aquela que faz atos desmedidos, loucos, insanos e indevidos. Essa não é a mãe! Clara voltou para a ONG fora da posição de mãe tal como ela era idealizada pela $O N G$ e pelas políticas públicas.

Podemos afirmar, ao colocarmos as questôes da psicanálise, que mãe é o contrário de mulher. A mulher "é o Outro que encarna a ferida da castração, o Outro atingido em sua potência” (Santiago, 2015, p. 76). A mãe tem o falo. A mãe tem o bebê. Miller nos esclarece o que seria a verdadeira mulher para a psicanálise:

Uma verdadeira mulher é o sujeito quando não tem nada - nada a perder. Uma verdadeira mulher, ao modo de Lacan, não recua diante de nada, diante de nenhum sacrifício, quando o mais precioso está em jogo - ali onde o homem, obnubilado, emaranhado pelo que tem a perder, não segue adiante, desvia o olhar, passa a outra coisa (Miller, 2015c, p. 10).

Essa mulher descrita acima por Miller, por não ter nada, não tem nada a perder e não fecha os olhos diante disso. A mãe, como diz Miller ao se referir a Lacan (1956-1957/1998) no Seminário: livro 4, é o Outro da demanda, o Outro "todo poder" que pode conceder ou não, responder ou não, é o outro que tem a riqueza, detém a linguagem, tem a abundância. A criança pede à mãe e é a mãe quem pode oferecer. Diferente da mãe, a mulher, no inconsciente, é a pobre, a difamada, o "Outro do não ter", aquela que é agredida, violada, difamada, censurada, silenciada [...] Quando ela é enaltecida, é na sombra da maternidade, daquela que nutre uma criança ou um homem. A mulher "é o Outro desejável, o Outro do desejo" (Miller, 2015b, p. 14). Miller declara que, se quisermos fazer 
uma oposição entre mãe e mulher, podemos dizer, em primeiro lugar, que "a mãe é o Outro da demanda e a mulher é o Outro do desejo" (Miller, 2015b, p. 14).

Miller afirma que a mulher no inconsciente, a mulher do desejo, que está diretamente relacionada à castração e à falta, são várias, ou melhor, cada uma é uma, "são todas diferentes na medida que encarnam a diferença como tal [...] ao passo que a mãe, esta é uma e toda. Se Lacan disse que 'A mulher não existe', foi para mostrar que a mãe, por sua vez, existe. Há (Il y a) a mãe" (Miller, 2015b, p. 19).

Verificamos que Clara não foi difamada pelas adolescentes na conversação, mas foi colocada como aquela que era impotente diante das circunstâncias. A impotência e a incapacidade estavam mais do lado de uma mulher que de uma mãe. Ao mesmo tempo, ao lermos os textos acima referidos, será que poderíamos afirmar que há uma mãe, uma mãe impotente, uma "não toda mãe"? (Miller, 2015b, p. 20).

Devemos aqui separar o olhar das adolescentes do olhar da instituição, pois a instituição sabia das possibilidades de ser uma "boa mãe". A escolha de Clara não foi a escolha das políticas públicas, ela foi aquela que "não quis a boa saída", não quis a maternidade, que era o lugar estabelecido pelas políticas públicas como uma boa solução.

Assim podemos distinguir a percepção das adolescentes, em que a mulher estava sob a sombra da mãe, demonstrado quando elas disseram do sacrifício materno feito por Clara, do entendimento da instituição e das políticas públicas que supunham, na maternidade, uma saída, uma solução não aceita por aquela adolescente. Foi importante esclarecer o ideal imaginário de maternidade existente na atualidade. Sabemos que o modo como a maternidade é vista hoje também foi uma construção. Badinter (2000) descreve como esse ideal de mãe foi uma construção ao longo dos tempos. Apesar das várias mudanças ocorridas em relação à mulher e à maternidade, na atualidade, a maternidade ainda é vista como um ideal, e as políticas públicas confirmam isso.

Ao decidir sair da instituição usando a palavra, Clara fez diferente do primeiro momento em que ela evadira, em que a ação prevalecera. Para sair da instituição de um outro modo, ela precisou dizer. Quando ela disse, algo de seu lugar como sujeito ficou preservado, lugar no qual decidiu por si mesma. Essa decisão de sair da instituição e deixar seu bebê não foi considerada, pelas políticas públicas, uma decisão favorável, preestabelecida, reconhecida como um lugar ideal de mãe. De acordo com as políticas, ela tomou uma decisão insana, incoerente e indevida, não somente porque ela estava em um abrigo, aos cuidados da instituição, que vinha trabalhando para ela ser acolhida pela avó, mas também porque o adolescente 
era visto como aquele a ser conduzido. Os atos decididos por estes são tratados como indevidos ou precipitados, e Clara, de forma planejada e organizada, foi até a coordenadora da ONG, ao Juiz e deixou seu bebê sob a tutela da lei.

Ao fugir da instituição, Clara fez um acting out, uma cena que demandou um espectador, direcionada ao Outro, um apelo. A instituição, a partir desse acting, ficou às voltas com a evasão de Clara, tentando reverter sua ação. Parece-nos que esse movimento, essa decisão da instituição em reverter a situação não respondeu às questôes de Clara e não fez uma inscrição no Outro. Sabemos que as passagens ao ato e os acting podem fazer ou não uma inscrição no Outro. Clara nos disse, após a reunião com os familiares, que não haveria uma boa resposta para o que acontecera. Não seria a decisão de Clara uma resposta a uma não inscrição no desejo do Outro? Seria uma "recusa ao Outro"?

Lacadée (2007b, p. 6) afirma que o adolescente é sempre moderno, é moderno "em relação às pulsões que agem nele", e que é preciso que o Outro "autentique" esse novo que surgiu, que diga sim. Não basta a um pai dizer não, é necessário que um pai diga sim ao novo que surge em uma criança ou em um adolescente. Podemos nos perguntar se Clara precisaria dessa autenticação do Outro, um sim diante da sexualidade que se apresenta, "ela volta com uma roupa diferente, curta e não sabemos onde dormiu”.

Ela não foi considerada destemida pelas adolescentes ao evadir, mas corajosa quando a decisão passou pela palavra, quando ela disse. Quando ela pôde responder por si, não como infratora, aquela que fugia, evadia, mas quando ela respondeu por sua decisão e assinou por isso dentro da lei. Quando ela se responsabilizou. As adolescentes, ao dizerem que ela foi corajosa, nos contaram que, para elas, a "sombra da mãe recaiu sobre a mulher" (Miller, 2015b, p. 14). Essa foi uma resposta das adolescentes à decisão de Clara, não era um sim ao ser de mulher, mas um sim ao sacrifício da mãe.

Clara respondeu à ONG de um modo considerado indevido, insensato pelas políticas públicas. Contudo, ao considerarmos a psicanálise e a palavra, avaliamos que não foi uma resposta desmedida. O que ela nos disse, sem enlouquecer, fazendo um contraponto a Freud, é que a maternidade não dava a ela o contorno ou a resposta sobre o seu ser de sujeito, que um bebê não respondeu à falta, à castração, ele não ocupou o lugar de substituto do falo. Neste fragmento, diferente dos anteriores, podemos concluir que a adolescente recusou a maternidade e que esta não respondeu ao seu ser de mulher e nem deu a ela um lugar na relação com a família. Os acting, evadir, ir para a rua também não deram a ela um lugar no desejo do Outro. Diferente dos casos anteriores, não houve inscrição no Outro. Não houve uma "boa resposta" do Outro. 


\section{CONSIDERAÇŌES FINAIS}

Apesar de todas as dificuldades que uma adolescente pode ter a partir de uma gravidez, em alguns casos, conforme demonstramos por meio dos fragmentos clínicos, as adolescentes puderam encontrar, depois desse acontecimento, um novo lugar social, familiar e foram acolhidas por uma instituição, recebendo abrigo, alimento e escola. Além disso, após a gravidez, cada uma pôde repensar a sua história e a sua relação com a vida. Assim, reafirmamos: é somente no caso a caso que podemos interrogar o sentido e a função da gravidez, a cada vez, com cada uma. Não há uma única reposta para todas, podendo ser a gravidez uma solução ou não, uma inscrição ou uma não inscrição.

Podemos considerar a gravidez na adolescência como uma resposta ao Outro? Seria a gravidez na adolescência um modo do adolescente responder ao que ocorre em seu corpo? Um modo de se dirigir ao Outro? Um acting out?

Podemos afirmar que cada uma delas, ao seu modo, precisou dar uma resposta à não inscrição no desejo do Outro. Os casos de Lívia e de Cris nos mostraram claramente esse fato. A primeira foi abandonada pela mãe, e a segunda nos disse que não tinha lugar, que mesmo sendo a filha mais velha e fazendo de tudo para ajudar a mãe, o lugar de filha ainda não pertencia a ela. Os acting dessas adolescentes poderiam ser uma resposta ao Outro, como nos disse Lívia sobre o abandono da mãe: "Eu enlouqueci".

As respostas dirigidas ao Outro apresentadas nos fragmentos clínicos não foram escutadas: ser andarilha pelas ruas da cidade conversando com os policiais (Júlia); ficar na rua agredindo as pessoas (Lívia); sair de casa em casa (Cris). Esses não foram apelos escutados pelo Outro, não fizeram um laço com menos risco, não houve inscrição.

Com a gravidez surgiu um novo lugar, a partir de um acting, escutado pela família, por outras famílias, pelas políticas públicas, pela instituição e pela sociedade. $\mathrm{O}$ acting é uma cena dirigida ao Outro e a gravidez é também, em alguns casos, uma ação dirigida ao Outro, é um acontecimento na adolescência para ser escutado. Os episódios de infração e violência não tiveram um efeito de inscrição. É somente com a gravidez que uma inscrição no desejo do Outro se faz. Assim, o Outro responde à gravidez e à maternidade, nomeando-a e ensinando-a a como existir no mundo, mas a partir dessa circunstância, grávida e mãe.

Surge um lugar em que a sombra da mãe recai sobre a mulher, como grávidas e mães as adolescentes têm um lugar de honra, mas não de mulher. Essa questão responde muito bem ao que Lacan nos ensina sobre a disjunção entre a mulher e a mãe, demonstrado no fragmento de Clara. Clara evidenciou que a sexualidade das adolescentes, seu lugar de mulher, não pôde aparecer, mas o lugar de mãe 
sim. Em Lívia isso também se apresentou ao localizarmos os modos como ela nomeou seu lugar de mãe. As adolescentes podiam ocupar, a partir da gravidez e da maternidade, o lugar da mãe, que existia e elas tinham, mas não o lugar de mulher.

Sobre gravidez e maternidade, as adolescentes nos disseram que a questão da gravidez na adolescência não se definia inteiramente por sua precocidade, suas complexidades eram diversas. São múltiplos os motivos pelos quais muitas adolescentes engravidam, entre eles: a falta de informação e oportunidades, a vontade própria, as expectativas sociais e a violência sexual. É fundamental que as políticas públicas contemplem medidas para lidar com essa realidade, levando em consideração a dimensão do sujeito. A gravidez na adolescência constitui um problema social que diz respeito ao Estado e à sociedade. Além disso, as construções sociais e os significados culturais da adolescência e da sexualidade permanecem enraizados em estruturas tradicionais que reforçam a maternidade, a desigualdade entre os gêneros e o não reconhecimento nem exercício dos direitos sexuais e direitos reprodutivos. Os contextos de pobreza, violência e Modernidade tornam essa situação ainda mais complexa. Entretanto, se por um lado, devemos considerar a gravidez na adolescência como uma questão que concerne às políticas públicas, por outro, precisamos interrogar o sentido e a função da gravidez para cada adolescente e de que modo incluir a dimensão do sujeito e a singularidade da gestação na adolescência nas políticas públicas dirigidas a adolescentes. 


\section{REFERÊNCIAS}

Alvarez, J. M. (2005). La pareja e el amor: conversaciones clinicas com Jacques Alain-Miller em Barcelona. Buenos Aires: Paidós.

Badinter, E. (2000). O amor incerto. Lisboa: Relógio D’Água.

Freda, D. A. (2015). Eladolescente atual: nociones clínicas. San Martín: Universidad Nacional de Gral, Unsam Edita, Fundacíon Cipac.

Freud, S. (1905). Os três ensaios sobre a sexualidade infantil. In J. Salomão (Trad.), Edição standard brasileira das obras psicológicas completas de Sigmund Freud (Vol. 7, pp. 123-252). Rio de Janeiro: Imago, 1996. (Publicado originalmente em 1905).

Freud, S. (1914). Algumas considerações sobre a psicologia do Escolar. In J. Salomão (Trad.), Edição standard brasileira das obras psicológicas completas de Sigmund Freud (Vol. 13, pp. 281-288). Rio de Janeiro: Imago, 1996. (Publicado originalmente em 1914).

Hartl, J. (2017, 18 agosto). 1960: primeira pílula anticoncepcional chega ao mercado. Revista DW: Made for Minds. Recuperado a partir de http:// www.dw.com/pt-br/1960-primeira-pílula-anticoncepcional-chega-aomercado/a-61 1248

Lacan, J. (1948). A agressividade na psicanálise. In V. Ribeiro (Trad.), Escritos (pp. 104-126). Rio de Janeiro: Jorge Zahar, 1998. (Publicado originalmente em 1966).

Lacan, J. (1956-1957). O seminário: livro 4: a relação de objeto. Rio de Janeiro: Jorge Zahar, 1998. (Publicado originalmente em 1956-1957).

Lacan, J. (1966). O estádio do espelho como formador da função do eu: tal como nos é revelada na experiência clínica. In V. Ribeiro (Trad.), Escritos (pp. 96-103). Rio de Janeiro: Jorge Zahar, 1998. (Publicado originalmente em 1966).

Lacadée, P. (2007a, maio/outubro). A passagem ao ato nos adolescentes. Revista Eletrônica do Núcleo Sephora, 2(4). Recuperado a partir de http://www.isepol. com/asephallus/numero_04/traducao_02.htm

Lacadée, P. (2007b). No espírito da conversação interdisciplinar: um jogo da vida. CIEN-Digital, 1 (7). Recuperado a partir de http://www.institutopsicanalise$\mathrm{mg} . \mathrm{com} . \mathrm{br} /$ ciendigital/pdf/CIEN-Digital01.pdf 
Laia, S. (2015). O que Medeia nos ensina sobre as mães, hoje? Curinga. Maternidades Contemporâneas, 40, 23-34.

Miller, J. A. (2012a). A criança e o saber. Rev. Cien-Digital, (11), 5-9. Recuperado a partir de http://minascomlacan.com.br/wp-content/uploads/2015/02/ CIEN-Digital-11.pdf

Miller, J. A. (2012b). Os seis paradigmas do gozo. Opção Lacaniana (nova série), 3(7), Recuperado a partir de http://opcaolacaniana.com.br/pdf/numero_7/ Os_seis_paradigmas_do_gozo.pdf

Miller, J. A. (2014). Jacques Lacan: observaçōes sobre seu conceito de passagem ao ato. Opção Lacaniana (nova série), 5(13), Recuperado a partir de http:// www.opcaolacaniana.com.br/pdf/numero_13/Passagem_ao_ato.pdf

Miller, J. A. (2015a). Em direção à adolescência. [S.l.]: Minas com Lacan. Recuperado a partir de http://minascomlacan.com.br/publicacoes/em-direcaoa-adolescencia/

Miller, J. A. (2015b). Mãe-mulher. Opção Lacaniana, 71, 13-21.

Miller, J. A. (2015c). Medeia a meio-dizer. Opção Lacaniana, 71, 9-11.

Miranda, M., Vasconcelos, R. \& Santiago, A. L. (2006). Pesquisa em psicanálise e educação: a conversação como metodologia de pesquisa. Psicanálise, Educação e Transmissão, 6. Recuperado a partir de http://www.proceedings.scielo.br/ scielo.php?pid=MSC0000000032006000100060\&script=sci_arttext

Nogueira, A. (2009). A evolução dos contraceptivos em imagens. Hype Science. Recuperado a partir de http://hypescience.com/23788-a-evolucao-doscontraceptivos

Santiago, J. (2015). Mãebebê ou mãemulher. Revista Curinga. 40, 73-86. (Maternidades Contemporâneas). 